\title{
La Formación MIR como frontera de la licenciatura de medicina
}

\author{
Francisco Pérez Jiménez \\ Catedrático y Jefe de Servicio de Medicina Interna, Hospital Universitario Reina Sofía. Universidad de Córdoba.
}

La educación médica debería garantizar la formación de profesionales competentes, que respondan a las necesidades de eficacia y eficiencia del sistema sanitario. Para conseguirlo se deberían definir previamente las competencias que se desean alcanzar (outcome based education), además de garantizar que el alumno aprender a aprender, ya que el $90 \%$ de los conocimientos que utilizará para su ejercicio profesional los deberá adquirir de modo autónoma, frente a sólo el 10\% que proceden de una enseñanza reglada. Finalmente, el pregrado debería estar integrado en el proceso formativo global del médico, que incluye su preparación como especialista, como investigador y el mantenimiento de $\mathrm{su}$ competencia profesional a lo largo de su vida, con la formación continuada. Este complejo proceso permite entender la relevancia que tiene la continuidad del proceso formativo. Y es precisamente en este contexto donde es clave el diseño de una prueba adecuada para pasar del pregrado a la especialización.

Teóricamente, a esta prueba se le deberían pedir varias características. En primer lugar sería deseable que fuera objetiva, permitiendo seleccionar a los mejores. Adicionalmente, debería tener en cuenta el rendimiento académico del alumno a lo largo de la licenciatura, como reflejo de la constancia y continuidad de su dedicación al estudio. También debería poder discernir las aptitudes del futuro especialista, lo que incluiría su dedicación, su vocación, la presencia de valores tales como su sentido ético y su profesionalismo. Finalmente, y como componente clave, la prueba en cuestión debería evaluar su preparación como profesional, incluyendo las competencias, tanto las cognitivas como las habilidades y las actitudes, incluyendo lo que el médico será capaz de hacer, como abordaría su práctica y su formación como profesional. Por supuesto, sería de desear que dicha prueba se hiciera respetando el equilibrio de las materias de su curriculo de licenciatura. Sin duda, dada la complejidad que tiene la formación médica, es casi imposible disponer de una prueba satisfactoria, que cumpla todos estos requisitos. Sin embargo es muy importante que sea lo más completa posible, entre otros argumentos porque será clave para la promoción del conocimiento y la orientación del aprendizaje a lo largo del pregrado, tanto para el profesor, dirigiendo su enseñanza, como para la motivación del alumno, quien orientará su esfuerzo en función de dicha prueba.

En el momento actual, la prueba MIR no cumple la mayoría de esos requisitos. Ciertamente es objetivo, y esa es su principal condición, lo que justifica su prestigio y el que sea considerado un ejemplo de imparcialidad. También incluye el rendimiento académico a lo largo de la licenciatura, reconociendo por tanto el esfuerzo y dedicación. Sin embargo, en la distribución de sus contenidos no se atiene al peso curricular de las distintas materias, como tampoco garantiza la evaluación de las competencias que no sean cognitivas. Esta última condición es especialmente preocupante, por la carencia de procedimientos para conocer las habilidades y la capacidad del médico para actuar como profesional, con la consiguiente influencia negativa en el producto educativo de nuestras facultades. En un estudio que hemos concluido recientemente, realizado en alumnos de sexto de medicina, el rendimiento que alcanzaron los estudiantes en una prueba tipo MIR no se correlacionaba con la obtenida en distintas pruebas para evaluar las diferentes competencias clínicas, incluyendo su capacidad para el manejo de un paciente simulado, o la interpretación de pruebas radiológicas. Esto resulta descorazonador, máxime cuando en el horizonte no se vislumbra una solución a esta ruptura entre lo que el estudiante debe saber y lo que se le pide para hacerse especialista.

Actualmente podemos decir que la prueba de acceso a la especialización supone una ruptura total con el concepto de continuidad que debería tener la carrera de Medicina, iniciada en la licenciatura y concluida con la jubilación del profesional. Adicionalmente, existe una ruptura entre las peculiaridades educativas del pregrado con la etapa MIR. En el primero la formación se centra en los aspectos cognitivos, siendo muy escasa la adquisi- 
ción de habilidades y actitudes clínicas, al contrario de lo que sucede en la especialización. La utilización de las fuentes de conocimientos, la tutorización personalizada y la capacidad para aprender de modo autónomo están bastante desarrolladas en el periodo MIR, y casi ausentes en el pregrado. Finalmente, la evaluación tiene una fuerte presencia en la etapa de estudiante, mientras que está totalmente ausente en la especialización, y las dos carecen de algo tan básico como una adecuada pormenorización de sus objetivos educativos. La consecuencia es que ambas etapas están sometidas al riesgo de la enseñanza oportunista, influenciables por el personalismo de los docentes y el voluntarismo del discente.

Por tanto, entre ambos procesos, con sus consiguientes deficiencias, existe un gran abismo, aunque en el caso del MIR el resultado sea mejor, en gran medida porque la enseñanza, aunque no se evalúa, está basada en el entrenamiento clínico de profesionales con una fuerte formación teórica, con un resultado final es aceptable.

Las consecuencias negativas de esta situación, afectan tanto a los alumnos como al profesorado de la propia Facultad. De una parte, desmotiva al profesor, generando una dicotomía entre los intereses del alumno, que estudia pensando en examen MIR, y los del propio centro, que no se implica en la educación integral del estudiante, con lo que se pierde gran parte del potencial disponible. Pero además, la situación se agrava por la disfunción de la estructura docente de los Hospitales universitarios, donde no hay conciencia de la importancia que tienen las prácticas, acentuada por el precario sistema de profesores asociados, colectivo en el que se incluyen profesionales totalmente desinteresados, junto al voluntarismo encomiable de otros, que en ocasiones ni siquiera son reconocidos como colaboradores y menos como profesores asociados. Ello explica que los estudiantes sean con frecuencia meros circulan- tes pasivos, en lo que se ha denominado el turismo hospitalario o el alumno transparente.

La situación es, en algunos centros, especialmente compleja, complicada por la falta de sintonía entre las autoridades universitarias y las del sistema sanitario, sin que se atisbe una solución fácil. El primer hecho que merece mencionarse es la falta de interés por dar prioridad a la solución de estos problemas, por las autoridades responsables. Tras varios años de ser publicada la LOPS, siguen sin existir decretos firmes que planteen el modelo futuro del profesor universitario o el del hospital universitario. Tampoco se ha abordado el compromiso legal para incluir pruebas de habilidades clínicas en el examen MIR, a lo que la respuesta es la de un profesor acomodado o decepcionado y un estudiante desinteresado, pensando sólo en su prueba para acceder a la especialidad, y no en ser buen médico. Muchos creemos que el modelo de relación actual, entre las instituciones, está tan agotado que habría que dar un giro organizativo radical, ya que se corre el riesgo de desarrollar nuevos convenios marco, que mantengan la estructura de las comisiones mixtas, tan escasamente eficaces hasta ahora. En este contexto, la reciente publicación del profesor Ciril Rozman (Universidades de Ciencias de la Salud. Aspectos legales de una opción innovadora. Med Clin (Barc) 2005; 124:499-503) viene a significar una bocanada de aire fresco en la ineficiente estructura de la educación sanitaria. En mi opinión supone abrir una ventana al futuro, entre otras cosas porque la incorporación al Espacio europeo de educación superior nos va a obligar a garantizar la eficiencia de nuestro sistema educativo. Hasta ahora, desgraciadamente, todos los cambios van quedando para la siguiente legislatura que nunca llega, mientras algunas universidades intentan poner en marcha tímidos cambios, que chocan con barreras administrativas y normativas. 